\title{
Influence of sintering parameters on the microstructure and mechanical properties of nanosized 3Y-TZP ceramics
}

\author{
A.A. Palmeira ${ }^{1,2}$, M.P. Cangani ${ }^{2}$, D. Rodrigues Jr. ${ }^{2}$, K. Strecker $^{3 *}$, C. dos Santos ${ }^{1,4}$ \\ ${ }^{1}$ Universidade do Estado do Rio de Janeiro, Faculdade de Tecnologia, Resende, RJ, Brazil \\ ${ }^{2}$ Universidade de São Paulo, Escola de Engenharia de Lorena, Lorena, SP, Brazil \\ ${ }^{3}$ Universidade Federal de São João Del-Rei, Pç. Frei Orlando 170, 36307-352, S. J. del Rei, MG, Brazil \\ ${ }^{4}$ Universidade Federal Fluminense, Escola de Engenharia Industrial Metalúrgica de Volta Redonda, \\ Volta Redonda, RJ, Brazil
}

\begin{abstract}
The fracture toughness of 3Y-TZP ceramics obtained from a nanocrystalline powder with an optimized microstructure and highly transformable tetragonal grains was investigated. Samples of $\mathrm{ZrO}_{2}-3 \mathrm{~mol} \% \mathrm{Y}_{2} \mathrm{O}_{3}$ were sintered at temperatures between 1250 and $1400{ }^{\circ} \mathrm{C}$, with isothermal holding times of up to $16 \mathrm{~h}$. Samples sintered at $1250{ }^{\circ} \mathrm{C}$ exhibited relative densities ranging between $92 \%$ and $98 \%$, which increased with increasing isothermal duration, while samples sintered at 1300,1350 , or $1400{ }^{\circ} \mathrm{C}$ achieved densification higher than $98 \%$ for all isothermal treatments. Crystallographic analysis indicated the presence of a highly transformable $\mathrm{ZrO}_{2}$-tetragonal phase $(\mathrm{c} / \mathrm{a} \sqrt{2}=1.0148-1.0154)$ for all conditions studied. The average grain size ranged from $0.18 \pm 0.04 \mu \mathrm{m}\left(1250{ }^{\circ} \mathrm{C}-0 \mathrm{~h}\right)$ to $0.64 \pm 0.08 \mu \mathrm{m}\left(1400{ }^{\circ} \mathrm{C}-16 \mathrm{~h}\right)$, indicating activation energy of $141.3 \mathrm{~kJ} / \mathrm{mol}$ for grain growth and a growth exponent of 2.8. Both Vickers hardness (1025 to $1300 \mathrm{HV}$ ) and fracture toughness (4.0 to $\left.7.8 \mathrm{MPa} . \mathrm{m}^{1 / 2}\right)$ increased with increasing sintering temperature and time due to increased densification, reduced porosity, and maintenance of potentially high fracture toughness by the $t \rightarrow \mathrm{m}$ phase transformation.
\end{abstract}

Keywords: 3Y-TZP, nanosized powder, sintering, microstructure, $t \rightarrow m$ transformation toughening mechanism.

\section{INTRODUCTION}

The use of yttria-stabilized tetragonal zirconia-based ceramics, $\mathrm{ZrO}_{2}\left(\mathrm{Y}_{2} \mathrm{O}_{3}\right)$, also called Y-TZP, is widespread in the field of dentistry, among others, due to its biocompatibility, aesthetic characteristics and, in particular, its excellent mechanical properties [1,2]. In particular, a high fracture toughness results from the tetragonal to monoclinic $(t \rightarrow m)$ phase transformation that occurs in the wake field of a propagating crack and which is accompanied by a volumetric expansion of around $4 \%$ to 5\% [3,4]. This phase transformation in turn, generates stress fields in the ceramic matrix, which hinders crack propagation, thus improving fracture toughness. In general, ceramics with an average grain size of less than $100 \mathrm{~nm}$ are called nanocrystalline ceramics. With reduced grain sizes in the sintered body, nanocrystalline ceramics may have different properties and considerable merits compared to conventional ceramics [5]. In some cases, nanocrystalline ceramics are used as a base material for the development of components and sometimes are applied as a secondary phase (reinforcement) added to ceramic matrices, with the intention to improve the fracture toughness and sinterability of these materials. However, there are some problems associated with the use of nanocrystalline ceramic powders, in particular the difficulty of eliminating aggregates and agglomerates, as well as the

*Dhttps://orcid.org/0000-0001-6164-7906 difficulty of compaction and control of grain growth during the sintering process. Starting in the 1990s, a number of companies developed easily compressible $\mathrm{ZrO}_{2}$ nanosized powders, stabilized with $3 \mathrm{~mol} \% \mathrm{Y}_{2} \mathrm{O}_{3}$, with added binders $[6,7]$. Due to this scenario, a growing research interest exists to control grain growth during sintering and to evaluate the effects on the mechanical properties.

Complete densification of 3Y-TZP ceramics using micrometric or sub-micrometric powders can be achieved at sintering temperatures of $1500{ }^{\circ} \mathrm{C}$ or higher and isothermal holding periods. As a result, the increased diffusion may cause grain growth of the $\mathrm{ZrO}_{2}$ grains and lead to a loss of stability of the tetragonal phase, even allowing for heterogeneous grain growth. In consequence, a population of low tetragonality t'- $\mathrm{ZrO}_{2}$ grains is generated $[8,9]$ with a concomitant loss of transformation ability (fracture toughness) when the material is subject to tensile stresses at the crack tip of a propagating crack. The use of nanosized ceramic powders is of great scientific and technological interest due to their increased sinterability, which may reduce the sintering temperature and/or time, also resulting in extremely fine-grained microstructures with improved mechanical properties. In the case of $\mathrm{ZrO}_{2}$-based ceramics, using nanosized particles, an improvement of the fracture toughness by microcracking has been reported [6-9]. Therefore, the sintering cycle has to be carefully chosen in order to take advantage of the unique properties of nanostructured materials. Previous studies $[9,10]$ indicate that the effectiveness of the $t \rightarrow \mathrm{m}$ phase transformation of 
Y-TZP ceramics is associated with the transformability of the tetragonal grains present in the sintered material. This transformability is associated with shearing stresses present in the tetragonal anisotropic phase, which is more pronounced for structures with a high ratio of the lattice parameters ' $c$ ' and ' $a$ '. Thus, maximizing the fraction of transformable tetragonal grains in the region ahead of the crack tip allows for increased fracture toughness, and specifically for 3Y-TZP ceramics, grain sizes between 0.1 and $1.0 \mu \mathrm{m}$ should be targeted [9], as grain sizes outside this range notably present low transformability or spontaneous transformation [9].

In this work, the aim was to specifically investigate the effects of the sintering parameters on a 3Y-TZP nanoparticulate powder that allows for the unique metastability of highly transformable $\mathrm{ZrO}_{2}$-tetragonal grains, developing microstructures with an average grain size smaller than $1 \mu \mathrm{m}$ and correlating the densification, amount of tetragonal $\mathrm{ZrO}_{2}$ phase, and microstructure (grain growth) with the resulting mechanical properties of lowtemperature sintered $3 \mathrm{Y}$-TZP ceramics.

\section{EXPERIMENTAL PROCEDURE}

The starting powder used was a commercial nanosized 3Y-TZP powder (TZ-3YE, Tosoh) with a specific surface of $16.2 \pm 2.0 \mathrm{~m}^{2} / \mathrm{g}$, an average crystallite size of $40 \mathrm{~nm}$, and containing $3.6 \mathrm{wt} \%$ of binder.

Dilatometry and sintering of Y-TZP samples: 3Y-TZP bars $(4 \times 4 \times 8 \mathrm{~mm})$ and discs $(\varnothing 12 \times 3 \mathrm{~mm})$ were compacted by cold uniaxial pressing under applied pressures between 12 and $74 \mathrm{MPa}$ for $60 \mathrm{~s}$. The samples were sintered under two different conditions: a) the sinterability of the Y-TZP specimens was evaluated by dilatometry using a dilatometer (DIL-402C, Netzsch) under argon flux throughout the heating and cooling cycle, adopting a heating rate of $2{ }^{\circ} \mathrm{C} / \mathrm{min}$ up to the maximum sintering temperature of $1250,1300,1350$, or $1400{ }^{\circ} \mathrm{C}$; the shrinkage was measured by a linear variable differential transducer (LVDT) with a sensitivity of $0.01 \mathrm{~mm}$; and b) solid-state sintering, using an electrically heated furnace (F1650, Maitec), with a heating rate of $2{ }^{\circ} \mathrm{C} / \mathrm{min}$ up to the maximum sintering temperature of $1250,1300,1350$, or $1400{ }^{\circ} \mathrm{C}$ with various isothermal holding times up to $16 \mathrm{~h}$. Cooling to room temperature was done at a rate of $10^{\circ} \mathrm{C} / \mathrm{min}$.

Density and phase analysis: the relative green density of the compacted samples was determined by the ratio of the geometrical density of the samples and the theoretical density of the material $\left(\mathrm{Q}_{\text {th }}\right)$ of $6.05 \mathrm{~g} / \mathrm{cm}^{3}$. The density of the sintered samples was determined by the immersion method, using Archimedes' principle. The residual porosity was calculated by the following equation [11]:

$$
\mathrm{P}(\%)=\left[1-\left(\varrho / \varrho_{\mathrm{th}}\right)\right] \cdot 100
$$

The phase composition of the starting powders and sintered samples was determined by X-ray diffraction analysis using a diffractometer (XRD-6000, Shimadzu). The analysis was conducted with $\mathrm{CuK} \alpha$ radiation in the $2 \theta$ range of $20^{\circ}$ to $80^{\circ}$ with a step width of $0.05^{\circ}$ and a counting time of $3 \mathrm{~s} /$ position. The X-ray diffraction peaks were identified by comparison with the JCPDS files [12]. The monoclinic zirconia content at the sample surface $\left(\mathrm{F}_{\mathrm{M}}\right)$ was calculated by the integrated peak areas of the planes $(\overline{1} 11)_{\mathrm{M}}$ and $(111)_{\mathrm{M}}$ planes of the monoclinic phase, in relation to the peak area of the $(101)_{\mathrm{T}}$ plane of the tetragonal phase, according to [13]:

$$
\begin{aligned}
& \mathrm{X}_{\mathrm{M}}=\frac{(\overline{1} 11)_{\mathrm{M}}+(111)_{\mathrm{M}}}{(\overline{1} 11)_{\mathrm{M}}+(111)_{\mathrm{M}}+(101)_{\mathrm{T}}} \\
& \mathrm{F}_{\mathrm{M}}=\frac{1.311 \mathrm{X}_{\mathrm{M}}}{1+1.311 \mathrm{X}_{\mathrm{M}}}
\end{aligned}
$$

The calculations of the lattice parameters were done with the Rietveld refinement technique, using the FullProf Suite 3.0 software [14-16]. The tetragonality, expressed by the c/a ratio of the $\mathrm{ZrO}_{2}$ grains, of samples sintered at $1250{ }^{\circ} \mathrm{C} / 0 \mathrm{~h}$ and $1400{ }^{\circ} \mathrm{C} / 16 \mathrm{~h}$ was determined by the model proposed by Krogstad et al. [17, 18] valid for $\mathrm{ZrO}_{2}$ stabilized with different amounts of $\mathrm{Y}_{2} \mathrm{O}_{3}$. After sintering, both surfaces of the specimens were ground and polished successively with 9,6 , and $1 \mu \mathrm{m}$ diamond suspensions. The microstructures of the sintered samples were observed using a scanning electron microscope (SEM, JSM-5310, Jeol). Samples were thermally etched at $1250{ }^{\circ} \mathrm{C}$ for $15 \mathrm{~min}$ with a heating rate of $25{ }^{\circ} \mathrm{C} / \mathrm{min}$. The grain size distributions of the sintered samples were determined using the ImageJ software. A population of at least 400 grains was analyzed for each sintering condition studied.

Mechanical properties: Vickers hardness of the sintered 3Y-TZP specimens was measured using a hardness testing equipment (Time Hardness). The polished surface of the samples was indented with a load of $1000 \mathrm{gf}$ for $30 \mathrm{~s}$, conducting 30 measurements $(n=30)$ for each sintering condition studied. Furthermore, the fracture toughness $\left(\mathrm{K}_{\mathrm{Ic}}\right)$ was also measured by the crack length emanating from the Vickers indentation marks, as proposed by Niihara et al. [19]:

$$
\mathrm{K}_{\mathrm{Ic}}=0.0089\left(\frac{\mathrm{E}}{\mathrm{HV}}\right)^{2 / 5}\left(\frac{\mathrm{F}}{\mathrm{a} .1^{1 / 2}}\right)
$$

where $\mathrm{K}_{\mathrm{Ic}}$ is the fracture toughness $\left(\mathrm{MPa} \cdot \mathrm{m}^{1 / 2}\right), 1$ is the length of the crack, measured from the tip of the indentation until the tip of the crack $(\mu \mathrm{m})$, a is the half-length of the indentation diagonal $(\mu \mathrm{m}), \mathrm{HV}$ is the Vickers hardness (GPa), E is Young's modulus of 3Y-TZP (195 GPa), and F is the indentation load used in the Vickers hardness test $(\mathrm{N})$.

\section{RESULTS AND DISCUSSION}

Characterization of starting-powder: Fig. 1 shows the $\mathrm{X}$-ray diffraction (XRD) pattern, the compaction curve, and 
an SEM micrograph of the zirconia powder used. A majority of the tetragonal $\left(\mathrm{t}-\mathrm{ZrO}_{2}\right)$ phase was found in the starting powder, as well as 18 vol\% of the monoclinic $\left(\mathrm{m}-\mathrm{ZrO}_{2}\right)$ phase (Fig. 1a). It can be noted from Fig. 1b that the material reached its maximum green density level for compaction pressures above $60 \mathrm{MPa}$, remaining constant for higher pressures. This behavior is believed to be the result of the binder present in the commercial powder. Furthermore, the SEM micrograph (Fig. 1c) shows that the starting powder consisted of spherical agglomerates with sizes ranging
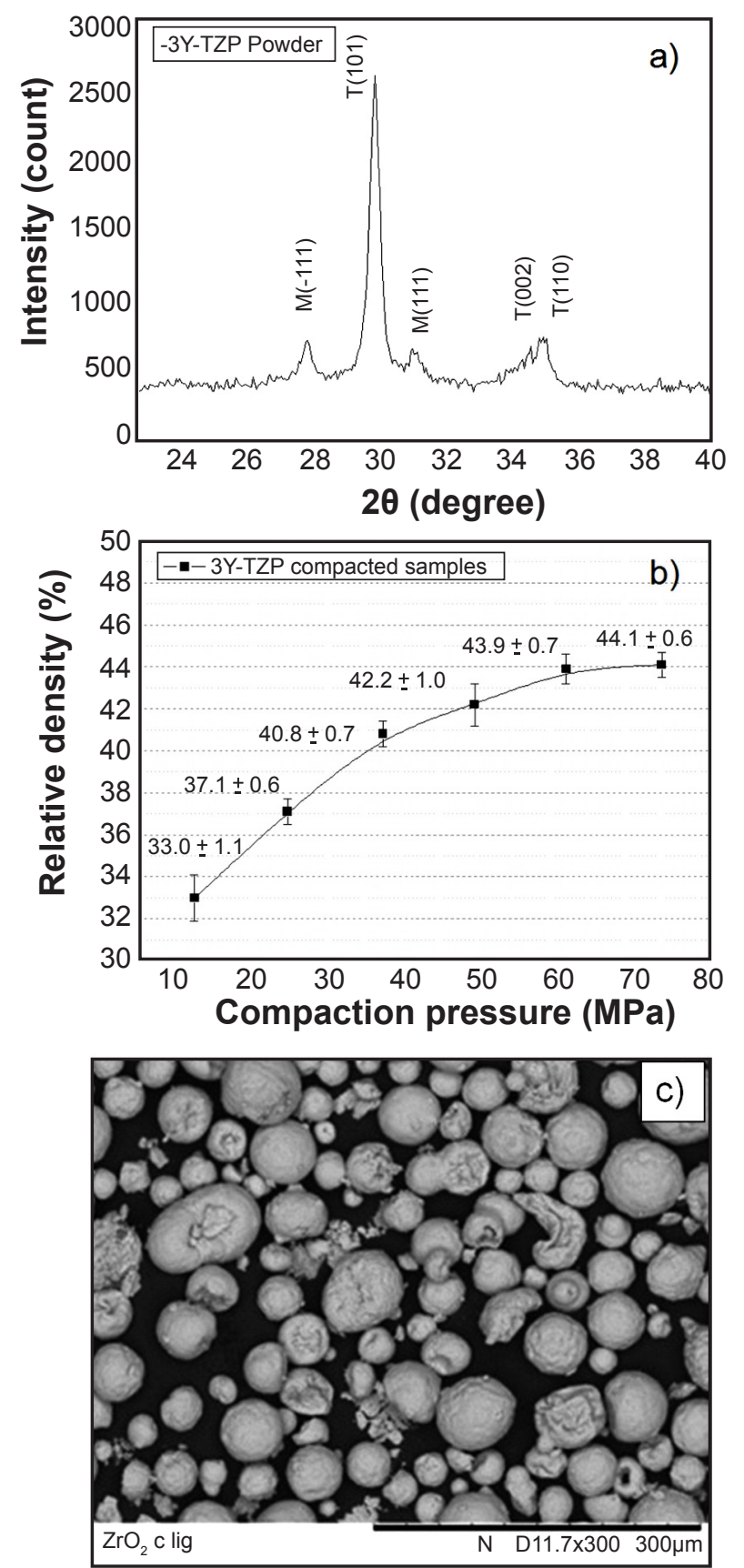

Figure 1: XRD pattern of the starting Y-TZP powder (a), green density as a function of the compaction pressure (b), and SEM micrograph of the Y-TZP powder highlighting agglomerates of varying size (c). between 20 and $50 \mu \mathrm{m}$, which were possibly formed during a spray-drying process of the powders with $3.6 \mathrm{wt} \%$ of binder added in order to facilitate the compaction process of this powder.

Dilatometry: Fig. 2a presents the linear shrinkage and shrinkage rate of a $\mathrm{ZrO}_{2}$ sample as a function of the sintering temperature up to $1400{ }^{\circ} \mathrm{C}$, while Fig. $2 \mathrm{~b}$ presents a comparison of the shrinkage rate of two samples compacted at the lowest and highest pressure of 12.3 and $73.5 \mathrm{MPa}$ investigated in this work and sintered at $1400{ }^{\circ} \mathrm{C}$ with an isothermal holding time of $60 \mathrm{~min}$. It was observed that at temperatures between 200 and $400{ }^{\circ} \mathrm{C}$, region I, a first shrinkage step occurred, corresponding to the elimination of the organic binder in the starting material. The highlighted region II comprised the effective onset of the densification process, where the solid-state sintering mechanisms acted eliminating porosity. In microparticulate Y-TZP ceramics, this region where densification usually begins is close to $1150{ }^{\circ} \mathrm{C}$ [20], while in nanocrystalline materials with a particle size of about $40 \mathrm{~nm}$, neck formation, and consequent densification and shrinkage occurred at temperatures close to $980{ }^{\circ} \mathrm{C}$. It can be noted that before the sintering isotherm begins, the effective shrinkage gain with increasing compaction pressure was about 2-3\%. Thus, for further studies in this work, a compaction pressure of $73.5 \mathrm{MPa}$ for the preparation of samples was chosen.
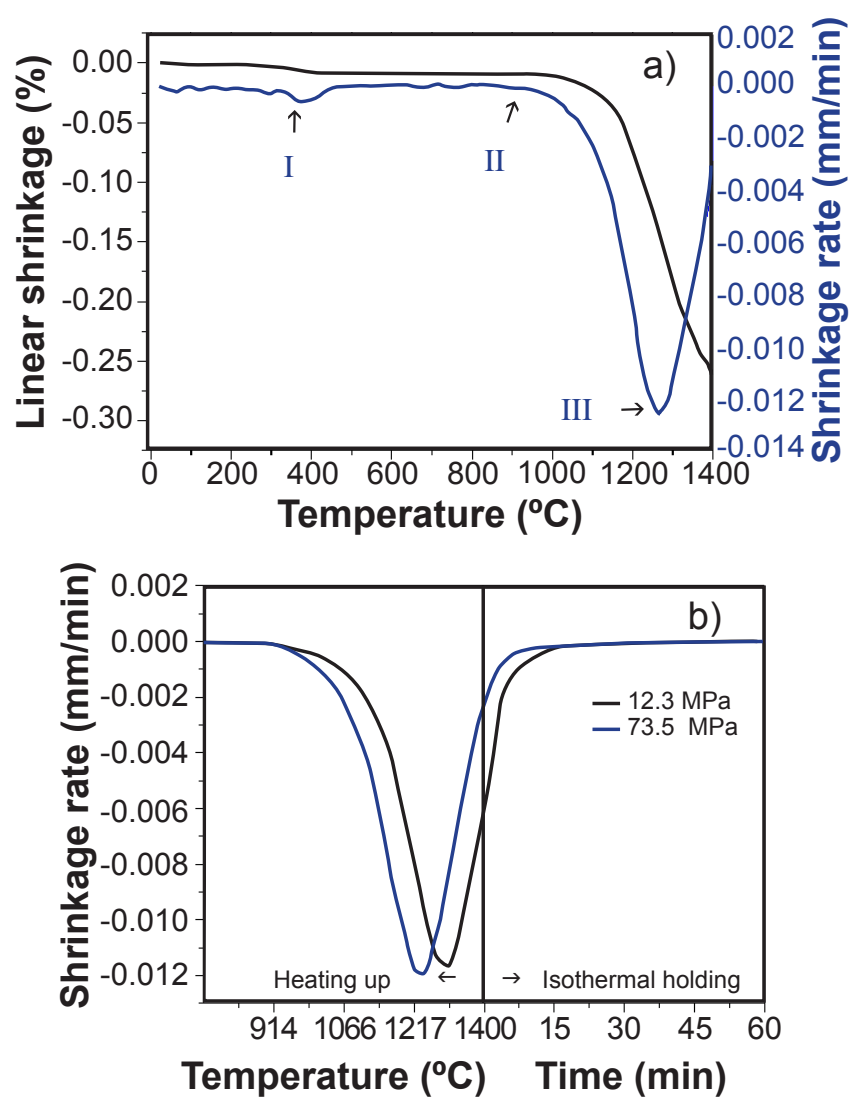

Figure 2: Linear shrinkage $\left(\mathrm{dL} / \mathrm{L}_{0}\right)$ and shrinkage rate as a function of the temperature of typical compacted 3Y-TZP sample (a), and shrinkage rate of $3 \mathrm{Y}$-TZP samples compacted with different pressures (final temperature of $1400{ }^{\circ} \mathrm{C}$ ) (b). 
Characterization of sintered bodies: the relative density and residual porosity results of the Y-TZP samples as a function of the sintering temperature are shown in Fig. 3 . The extremely fine, nanometric particle size of the zirconia starting powder used allowed for high densification to be reached during sintering. Under all sintering temperatures

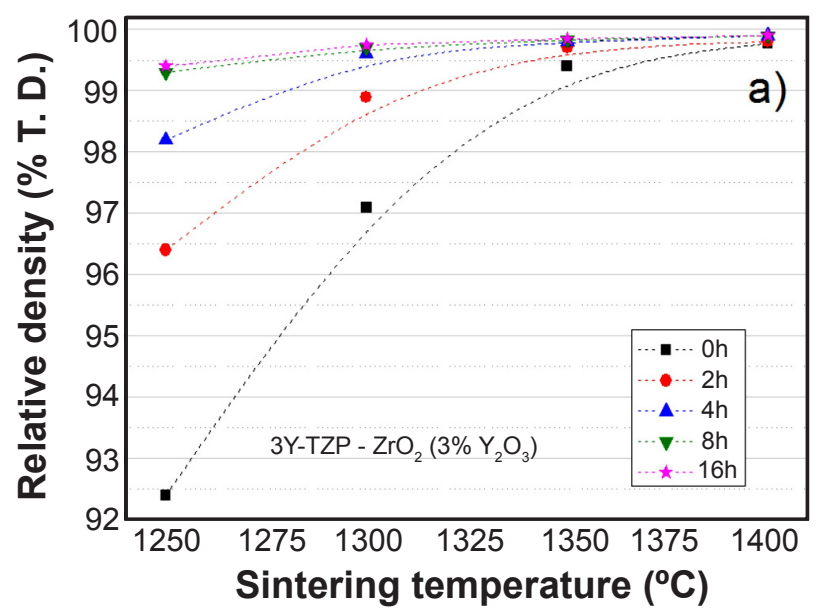

studied, relative densities higher than $92 \%$ were achieved, and for the sintering temperatures of 1350 and $1400{ }^{\circ} \mathrm{C}$, all samples exhibited relative density higher than $98 \%$, even without isothermal holding (Fig. 3a). At lower temperatures, 1250 and $1300{ }^{\circ} \mathrm{C}$, relative densities exceeding $98 \%$ were only obtained after an isothermal treatment for 16 or $8 \mathrm{~h}$,

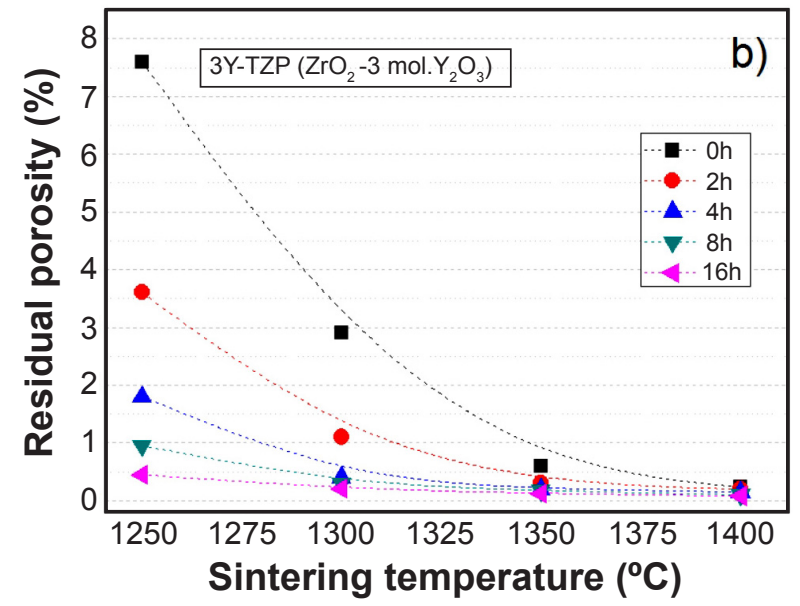

Figure 3: Relative density (a) and porosity (b) of 3Y-TZP sintered samples as a function of sintering temperature and isothermal holding time.
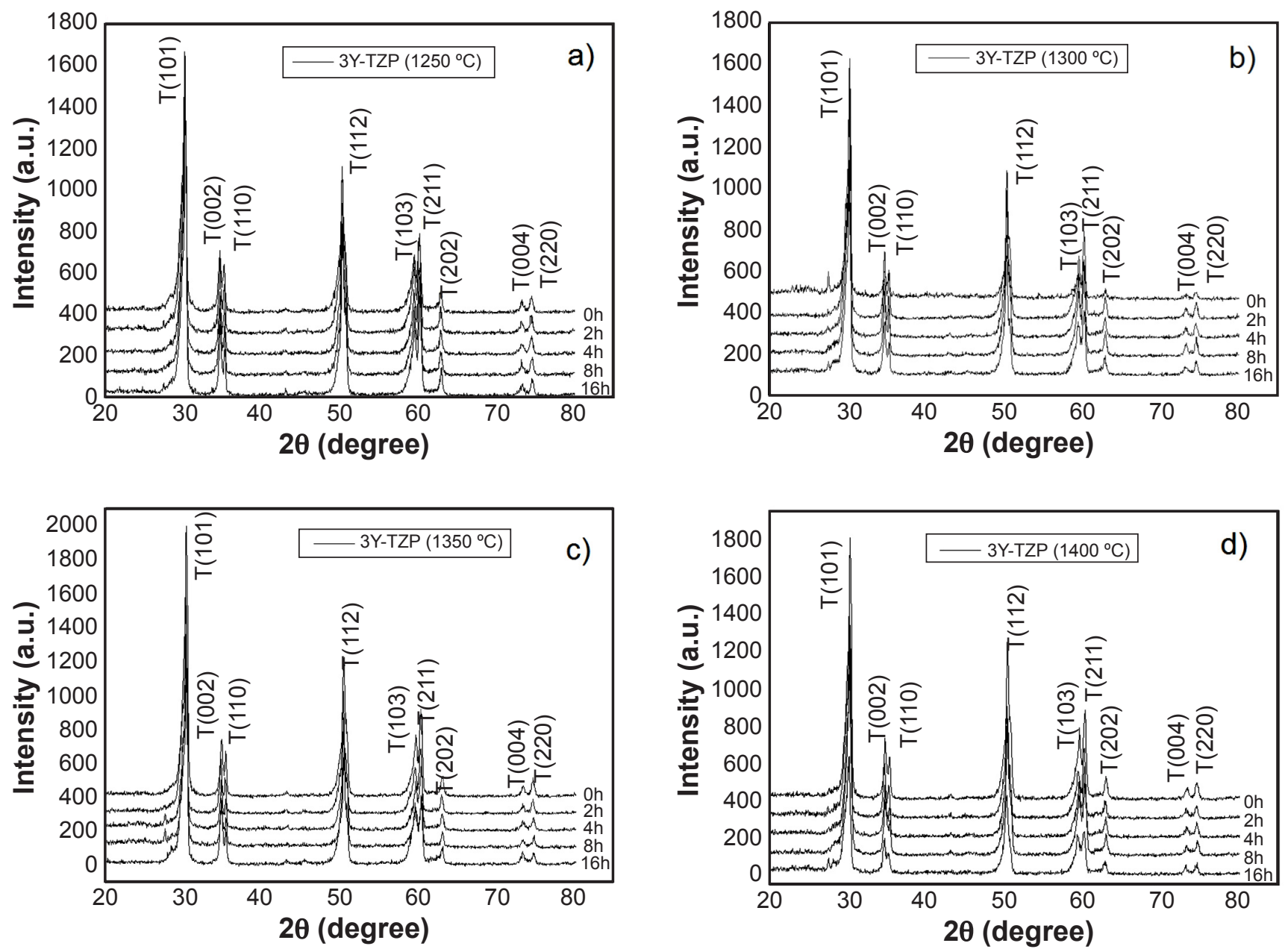

Figure 4: XRD patterns of 3 Y-TZP samples sintered at $1250{ }^{\circ} \mathrm{C}(\mathrm{a}), 1300{ }^{\circ} \mathrm{C}(\mathrm{b}), 1350{ }^{\circ} \mathrm{C}(\mathrm{c})$, and $1400{ }^{\circ} \mathrm{C}(\mathrm{d})$, with isothermal holding times of $0,2,4,8$, and $16 \mathrm{~h}$ 
Table I - Rietveld refinement of 3Y-TZP crystal structure after sintering at different temperatures.

\begin{tabular}{cccc}
\hline Parameter & $1250{ }^{\circ} \mathrm{C}-0 \mathrm{~h}$ & $1350{ }^{\circ} \mathrm{C}-8 \mathrm{~h}$ & $1400{ }^{\circ} \mathrm{C}-16 \mathrm{~h}$ \\
\hline & $\mathrm{a}=3.5956 \AA$ & $\mathrm{a}=3.5913 \AA$ & $\mathrm{a}=3.5904 \AA$ \\
Lattice parameters: tetragonal $\mathrm{ZrO}_{2}$ & $\mathrm{c}=5.1601 \AA$ & $\mathrm{c}=5.1570 \AA$ & $\mathrm{c}=5.1548 \AA$ \\
$\left(\mathrm{t}-\mathrm{ZrO}_{2}\right.$ ); space group $P 4_{2} / n m c(137)$ & $\mathrm{V}=66.711 \AA^{3}$ & $\mathrm{~V}=66.513 \AA^{3}$ & $\mathrm{~V}=66.451 \AA^{3}$ \\
Tetragonality $(\mathrm{c} / \mathrm{a} \sqrt{ } 2)[17,18]$ & 1.0148 & 1.0154 & 1.0152 \\
$\chi^{2}$ & 2.58 & 4.08 & 5.72 \\
\hline
\end{tabular}
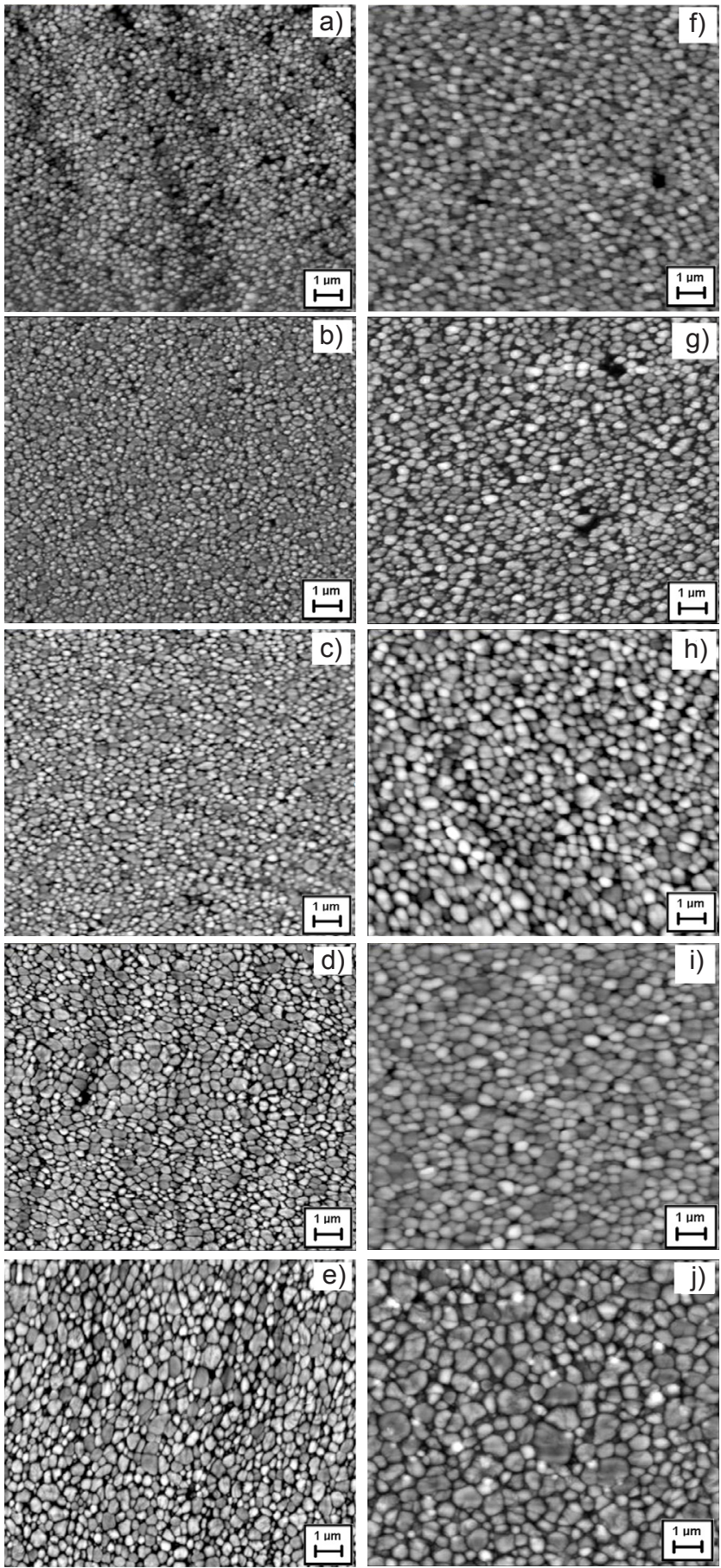

Figure 5: SEM micrographs of Y-TZP samples sintered at: $1250{ }^{\circ} \mathrm{C}$ for $0 \mathrm{~h}$ (a), $2 \mathrm{~h} \mathrm{(b),} 4 \mathrm{~h} \mathrm{(c),} 8 \mathrm{~h}(\mathrm{~d})$, and $16 \mathrm{~h} \mathrm{(e);} \mathrm{and} 1400{ }^{\circ} \mathrm{C}$ for 0 h (f), 2 h (g), 4 h (h), 8 h (i), and 16 h (j). respectively. Similarly, the residual porosity (Fig. 3b) was progressively reduced with increasing temperature and isothermal holding time.

The X-ray diffraction patterns of samples sintered at different temperatures and isothermal holding times are shown in Fig. 4. Similar diffraction patterns are observed in Fig. 4 for all samples showing only diffraction peaks of the tetragonal $\mathrm{ZrO}_{2}$ phase, independently of the sintering temperature or holding time investigated. Furthermore, no monoclinic $\mathrm{ZrO}_{2}$ was detected after sintering, indicating the complete conversion of this phase present in the starting powder (Fig. 1a) into tetragonal $\mathrm{ZrO}_{2}$. The results of the Rietveld refinement for the $\mathrm{t}-\mathrm{ZrO}_{2}$ lattice parameters and the calculated tetragonality of samples sintered at $1250{ }^{\circ} \mathrm{C} / 0 \mathrm{~h}, 1350{ }^{\circ} \mathrm{C} / 8 \mathrm{~h}$, and $1400{ }^{\circ} \mathrm{C} / 16 \mathrm{~h}$ are summarized in Table I. Scott [21], reporting on the $\mathrm{ZrO}_{2}-\mathrm{Y}_{2} \mathrm{O}_{3}$ binary system, indicates that $\mathrm{ZrO}_{2}$ ceramics stabilized with $3 \mathrm{~mol} \% \mathrm{Y}_{2} \mathrm{O}_{3}$ present the tetragonal phase with some associated cubic phase. However, in recent studies [17, 18], mathematical models associated with the $\mathrm{X}$-ray diffraction technique propose that an intermediate phase called $\mathrm{t}^{\prime}-\mathrm{ZrO}_{2}$, composed of grains containing network parameters ' $c$ ' approaching ' $a$ ', can coexist with the stabilized $\mathrm{t}-\mathrm{ZrO}_{2}$ phase when $3 \mathrm{Y}$-TZP is sintered at temperatures and times that allow for the migration of a part of $\mathrm{Y}_{2} \mathrm{O}_{3}$ to specific grains t', reported as 'semi-cubic'. In this way, a modification of the original unit cell structure may occur, which changes the relationship between the parameters $\mathrm{c}$ and a of certain grains. Thus, after determining the crystallographic parameters of sintered materials at different temperatures and holding times, the results shown in Table I indicated that the tetragonality (c/a ratio) of the materials underwent little variation, with values of $\mathrm{c} / \mathrm{a} \sqrt{2}$ of 1.015 , regardless of the sintering conditions. As a result, the tetragonality of the grains was not significantly altered by the sintering temperature and holding time studied.

Fig. 5 shows representative micrographs of samples sintered at 1250 and $1400{ }^{\circ} \mathrm{C}$ with isothermal holding times of $0,2,4,8$, and $16 \mathrm{~h}$. Furthermore, Fig. 6 a presents the average grain size as a function of the sintering temperature and isothermal holding time, and Fig. 6b shows a correlation between the grain size and the relative density of the sintered samples. The increase of the average grain size of the zirconia grains was observed with the increase of the sintering temperature and isothermal holding time (Fig. 6a). The grain size varied between $0.18 \pm 0.04$ and $0.45 \pm 0.07 \mu \mathrm{m}$ for samples sintered at $1250{ }^{\circ} \mathrm{C}$ without and $16 \mathrm{~h}$ isothermal 

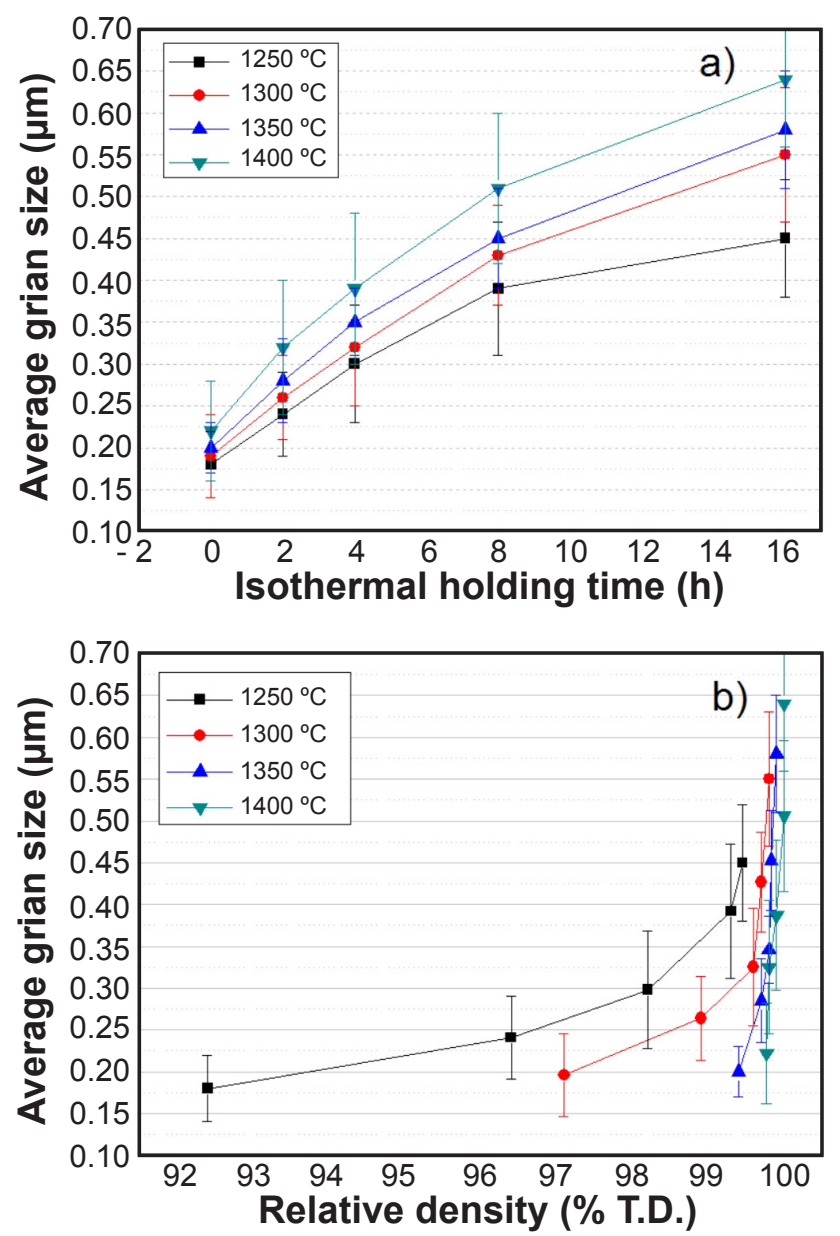

Figure 6: Grain size as a function of isothermal holding time at different temperatures (a), and the correlation between grain size and relative density (b) for Y-TZP ceramics.

holding time, respectively, and between $0.22 \pm 0.06$ and $0.64 \pm 0.08 \mu \mathrm{m}$ for samples sintered at $1400{ }^{\circ} \mathrm{C}$ without and $16 \mathrm{~h}$ isothermal holding time. The calculated grain growth exponent $(\mathrm{n})$ and the activation energy for grain growth $\left(\mathrm{Q}_{\mathrm{gg}}\right)$ were $\mathrm{n}=2.8$ and $\mathrm{Q}_{\mathrm{gg}}=141.3 \mathrm{~kJ} / \mathrm{mol}$ for the Y-TZP powder studied, indicating that grain growth was controlled by grain boundary diffusion $[7,20,22]$. In Fig. 6b, the average grain size is correlated to the relative density. The graph indicates that grain growth occurred simultaneously with the elimination of residual porosity at all sintering temperatures studied. Analyzing the shrinkage behavior obtained by dilatometry (Fig. 2), it was observed that at about $980{ }^{\circ} \mathrm{C}$, the densification process began, due to the high reactivity of the nanocrystalline powder, with crystallite sizes of around $40 \mathrm{~nm}$. From this temperature, until the final sintering temperatures $\left(1250\right.$ to $1400{ }^{\circ} \mathrm{C}$ ) were reached, diffusional mechanisms acted in the material, reducing the free internal surface area and eliminating porosity, besides initiating grain growth. On the other hand, the materials reached high densification levels, with relative densities higher than $92 \%$ and presenting average submicron grain sizes between 0.18 and $0.22 \mu \mathrm{m}$, with low size variations between sample groups.

In general, when the relative density exceeds $90 \%$
[23-28] during the sintering of submicron-sized particles, the bonding between the particles due to grain boundary formation is well developed, and most pores in the sintered body are closed. Furthermore, grain growth occurs until reaching the final sintering temperature and also during the isothermal holding time, as was the case in this work. Densification also continues to increase, although the few and well dispersed residual pores may still hinder grain growth kinetics during this stage. In consequence, first, the final average grain sizes of the sintered samples were very close and with only small variations due to the very small $\mathrm{ZrO}_{2}$ grains formed in the early sintering stage of nanocrystalline Y-TZP powders; second, the residual porosity (Fig. 3b) was low at the moment the isothermal threshold began $(\mathrm{t}=0)$; and, third, the sintering temperatures adopted in this study (1250$1400{ }^{\circ} \mathrm{C}$ ) allowed only a moderate diffusivity compared to the usual sintering temperatures of 1500 to $1600{ }^{\circ} \mathrm{C}[6,20]$. Therefore, the sintering of these nanoparticulate powders results in normal grain growth during the isothermal holding time, and refined microstructures were obtained under all sintering conditions studied.

Mechanical properties: in Fig. 7a, the Vickers hardness, and in Fig. 7b, the fracture toughness of sintered samples are presented as a function of the sintering parameters adopted. Furthermore, the relationship between the number of grains per unit area (grain density) as a function of temperature and isothermal holding time is shown in Fig. 7c. A slight increase in hardness was observed with increasing duration of the isotherm for all sintering temperatures (Fig. 7a). This behavior was associated with the increase in densification and reduction in porosity, as illustrated in Fig. 3. Porosity exponentially reduces the hardness of the material, and therefore, its elimination improves the final hardness of the sintered body. Finally, maximum hardness ranged from 1250 to $1300 \mathrm{HV}$, which are typical values for Y-TZPbased ceramics [29, 30]. The fracture toughness (Fig. 7b) also increased with increasing sintering temperature and isothermal holding time. The fracture toughness of zirconia based-ceramics is associated with three material characteristics: i) tetragonal phase content, ii) $\mathrm{ZrO}_{2}$ grain size, and iii) residual porosity. Microstructural analysis revealed average grain sizes ranging from 0.18 to $0.22 \mu \mathrm{m}$ for sintered materials without an isothermal threshold and 0.45 to $0.64 \mu \mathrm{m}$ for prolonged isothermal treatments. Different authors claim, based on previous studies, that dense, mostly tetragonal 3Y-TZP ceramics may have grains with different degrees of toughening effect by the $t \rightarrow m$ phase transformation [31-34]. Specifically, when the grain size is less than or near $100 \mathrm{~nm}$, the grains are highly metastable, tending to remain tetragonal even when exposed to a stress field generated by the crack propagation, thus without undergoing the $\mathrm{t} \rightarrow \mathrm{m}$ transformation toughening mechanism. On the other hand, materials with zirconia grains larger than $1 \mu \mathrm{m}$ tend not to exhibit thermodynamic metastability, leading to a spontaneous phase transformation or, in some cases, to a further transformation into the cubic phase, with depletion of $\mathrm{Y}$ in neighboring grains and generation 

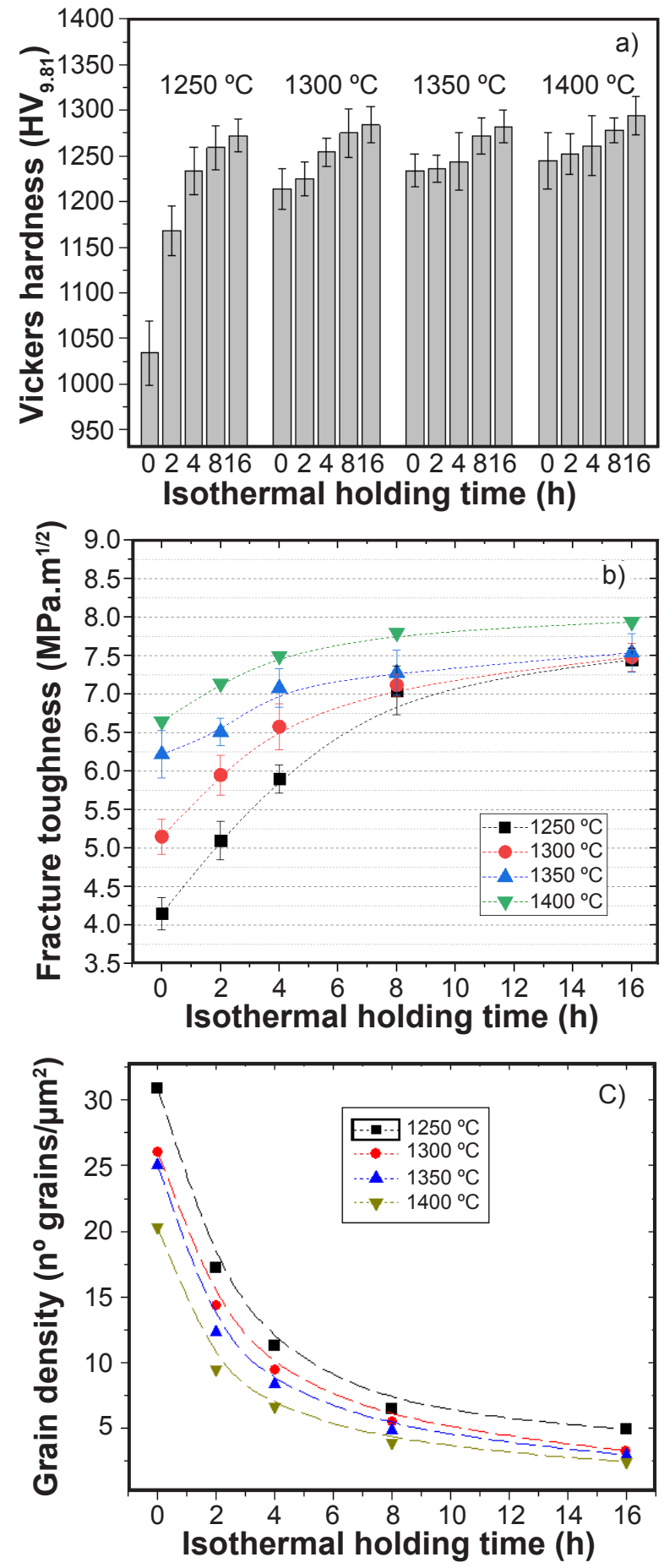

Figure 7: Vickers hardness (a), fracture toughness (b), and grain density (c) as a function of sintering temperature and isothermal holding time for the $3 \mathrm{Y}-\mathrm{TZP}$ sintered samples.

of monoclinic $\mathrm{ZrO}_{2}$. Consequently, materials exhibiting an average grain size close to these two limits tend to have reduced mechanical properties, especially with regard to fracture toughness. Fig. 7c shows the grain density as a function of sintering temperature and time. It was noted that without isotherm or for short isothermal periods, the number of grains per area was higher, regardless of the temperature. However, as already shown, many of these grains were of a very small size. For isothermal holding times longer than $4 \mathrm{~h}$, the grain density tended to stabilize, with grain sizes ranging from 0.35 to $0.64 \mu \mathrm{m}$. The third factor that significantly influences the fracture toughness of Y-TZP ceramics is the residual porosity (Fig. 3b). In the case of our work, an inverse proportional behavior of fracture toughness with the reduction of porosity was found, as confirmed by other works [35-37].

It is well established that the fracture toughness of tetragonal zirconia (Y-TZP) based ceramics is the result of its peculiar $\mathrm{t} \rightarrow \mathrm{m}$ phase transformation mechanism [9, 38]. This transformation occurs basically in two stages: transition of the tetragonal into the monoclinic structure due to the displacement of the $\mathrm{Zr}^{4+}$ ions, and the diffusion of oxygen ions to the oxygen sites in the monoclinic structure, causing monoclinic, longitudinal sheets grow within the tetragonal grain, just as they grow laterally due to the lateral migration of $\mathrm{O}^{2-}$ ions [39]. As a crack propagates, tensile stress is associated with the crack opening. The tetragonal grains adjacent to the crack tip undergo compression and create a stress zone associated with the applied mechanical stress. The variation of the total free energy for the transformation to occur is the energy balance between the variation of the free chemical energy, variation of surface free energy, and density of interaction energy (associated with the application of external energy) $[40,41]$. In the specific case of this work, for all sintered samples studied, the mechanical tests were carried out at room temperature, the chemical composition referring to the alloying oxide $\left(3 \mathrm{~mol} \% \mathrm{Y}_{2} \mathrm{O}_{3}\right)$ remained constant, and the energy of interaction was considered constant because the same indentation load was adopted in the tests. Thus, the transformation occurred mainly due to the factor related to the free surface energy; in other words, the tetragonal microstructure was the dominating factor in the transformation.

Considering that the $\mathrm{t}-\mathrm{ZrO}_{2}$ grains were the main parameter responsible for the fracture toughness of Y-TZP ceramics, the extent of the transformation region (shielding) around the crack tip was directly linked to the volumetric fraction of transformable $\mathrm{t}-\mathrm{ZrO}_{2}$ grains. In the specific case of this work, we adopted a microstructural design that allowed for a complete formation of transformable tetragonal grains, confirmed by the X-ray diffraction analysis that indicated a stable tetragonality of the grains, regardless of the sintering conditions adopted. As the tetragonality was not influenced within the limits of this study, the shear stress and consequent deformation induced by twinning did not significantly affect toughness. The results indicated that porosity was progressively reduced in the sintered Y-TZP ceramics due to the increase in temperature and isothermal holding time. Furthermore, it is expected that the elastic modulus undergoes proportional reduction with increasing porosity and that porosity reduces the effective phase transformation zone around the crack tip (shielding) because they represent voids which retain part of the cascade effect of shearing or compressive stresses resulting from transformed grains located in this region. The increment of toughness by plane 
deformation $\left(\Delta \mathrm{K}_{\mathrm{C}}\right)$ can be expressed by $[42,43]$ :

$$
\Delta \mathrm{K}_{\mathrm{C}}=0.22 . \mathrm{f} \cdot \mathrm{E} \cdot \mathrm{\varepsilon}^{\mathrm{t}} \cdot \frac{\sqrt{\mathrm{h}}}{1-v}
$$

where $f$ is the volume fraction of the tetragonal phase in the transformation zone, E is Young's modulus, $\varepsilon^{t}$ the dilatational deformation involved, $\mathrm{h}$ the size of the transformation zone, and $v$ the Poisson's ratio. According to this model, considering the microstructure and the porosity of the Y-TZP ceramics developed in this work, it can be stated that sintering at lower temperatures and shorter holding times results in higher porosity and smaller average grain size and therefore a reduction in the parameters $\mathrm{f}, \mathrm{E}$, and $\mathrm{h}(\mathrm{Eq}$. E). In addition, as there are no variations in the tetragonality and, therefore, the transformability of tetragonal grains can be considered similar, the parameter $\varepsilon^{t}$ can be considered constant, as well as the Poisson's ratio. On the other hand, the increase in the size of the tetragonal grains, on this dimensional scale, leads to a small increase in the effective transformation zone around the crack tip. Thus, within the experimental limits of this article, the toughening and, consequently, the fracture toughness of these materials containing smaller grain size and greater porosity is theoretically lower than dense materials with larger zirconia grains, corroborating the results presented in Fig. 7b.

\section{CONCLUSIONS}

The fracture toughness of ceramics obtained from a nanocrystalline $3 \mathrm{Y}$-TZP powder and sintering between 1250 and $1400{ }^{\circ} \mathrm{C}$ was investigated. Samples sintered at $1250{ }^{\circ} \mathrm{C}$ showed relative densities between $92 \%$ and $98 \%$, depending on the isothermal holding time. For sintering at 1350 and $1400{ }^{\circ} \mathrm{C}$, all samples exhibited relative density higher than $98 \%$, independent of an additional isothermal holding. The analysis by Rietveld's refinement indicated that the only crystalline phase present under all sintering conditions studied was $\mathrm{t}-\mathrm{ZrO}_{2}$, whose tetragonality enabled high transformability during activation of the $t \rightarrow m$ transformation toughening mechanism. In addition, the microstructural analysis revealed that the average grain sizes ranged from 0.18 to $0.22 \mu \mathrm{m}$ for sintered materials without an isothermal threshold and 0.45 to $0.64 \mu \mathrm{m}$ for prolonged isothermal treatments of $16 \mathrm{~h}$. The hardness increased proportionally with the reduction of the residual porosity, while the fracture toughness presented a progressive increase related to the increase in the sintering temperature as well as in the isotherm sintering (4 to 8 MPa. ${ }^{1 / 2}$ ). This behavior was due to the increase in the effective transformation zone around the crack tip, which is reported to increase with increasing average grain size, without losing its transformability, as well as the gradual reduction of residual porosity. Thus, an efficient strategy to densify nanoparticulate powders at low temperatures, obtaining a high fracture toughness, may be the use of isothermal holding times that result in refined and highly transformable microstructures.

\section{ACKNOWLEDGMENTS}

The authors would like to thank Manara Nogueira Quintino and Marcelo José Bondioli, for their help in the ceramographic sample preparation and dilatometric investigations. The authors, K. Strecker and C. Santos, would like to thank the Brazilian research funding agencies CNPq (grants $n^{\circ} 311119 / 2017-4$ and $n^{\circ} 305827 / 2016-2$ ) and FAPERJ (grants n ${ }^{\circ}$ E26-201.476/2014, $n^{\circ}$ E26-202 .997/2017 and $n^{\circ}$ E26-211.760/2015) for financial support of this work.

\section{REFERENCES}

[1] J. Chevalier, Biomaterials 27, 4 (2006) 535.

[2] J.R. Kelly, I. Denry, Dent. Mater. 24 (2008) 289.

[3] R. Stevens, Trans. J. Br. Ceram. Soc. 80 (1981) 81.

[4] B. Basu, J. Vleugels, O.V.D. Biest, Mater. Sci. Eng. A 366, 2 (2004) 338.

[5] C.C. Koch, J. Mater. Sci. 42, 5 (2007) 1403.

[6] H.C. Kim, I.J. Sho, I.K. Jeong, I.Y. Ko, R.Z.A. Munir, J. Mater. Sci. 42 (2007) 9409.

[7] G.B. Granger, C. Guizard, J. Am. Ceram. Soc. 90, 4 (2007) 1246.

[8] D.-J. Kim, J. Am. Ceram. Soc. 73 (1990) 115.

[9] B. Basu, Int. Mater. Rev. 50, 4 (2005) 239.

[10] S. Shukla, S. Seal, Int. Mater. Rev. 50, 1 (2005) 45.

[11] ASTM C 373-88, "Standard test method for water absorption, bulk density, apparent porosity and apparent specific gravity of fired whiteware products", Am. Soc. Test. Mater., West Conshohocken (2006).

[12] Joint Committee on Powder Diffraction Standard, "Inorganic materials", Int. Cent. Diffract. Data Swarthmore, Pennsylvania (1979).

[13] H. Toraya, M. Yoshimura, S. Somiya, J. Am. Ceram. Soc. 67 (1984) C183.

[14] J. Rodriguez-Carvajal, Physica B Condens. Matter. 192, 1-2 (1993) 55.

[15] R.J. Hill, C.J. Howard, J. Appl. Crystallogr. 20, 6 (1987) 467.

[16] J. Rodriguez-Carvajal, in $15^{\text {th }}$ Congr. IUCr, Toulouse (1990) 127.

[17] J.A. Krogstad, M. Lepple, Y. Gao, D.M. Lipkin, C.G. Levi, J. Am. Ceram. Soc. 94, 12 (2011) 4548.

[18] E. Camposilvan, R. Leone, L. Gremillard, R. Sorrentino, F. Zarone, M. Ferrari, J. Chevalier, Dent. Mater. 34, 6 (2018) 879.

[19] K. Niihara, R. Morena, D.P.H. Hasselman, J. Mater. Sci. Lett. 1 (1982) 1.

[20] A.A. Palmeira, M.J. Bondioli, K. Strecker, C. Santos, Ceram. Int. 42, 2 (2016) 2662.

[21] H.G. Scott, J. Mater. Sci. 10, 9 (1975) 1527.

[22] R. Chaim, Mater. Sci. Eng. A 486, 1-2 (2008) 439.

[23] J.R. Groza, in "Nanostructured materials: processing, properties and potential applications", W. Andrew Publ., New York (2002) 115.

[24] E.Y. Gutmanas, Prog. Mater. Sci. 34 (1990) 261.

[25] E.Y. Gutmanas, L.I. Trusov, I. Gotman, Nanostruct. 
Mater. 8 (1994) 893.

[26] H. Hahn, Nanostruct. Mater. 2,3 (1993) 251.

[27] Z.Z. Fang, H. Wang, Int. Mater. Rev. 53, 6 (2008) 326.

[28] M.J. Mayo, Mater. Des. 14 (1993) 323.

[29] R. Chaim, M. Hefetz, J. Mater. Sci. 39, 9 (2004) 3057.

[30] R. Stevens, Zirconia and zirconia ceramics, $2^{\text {nd }}$ ed., Twickenham Magnesium Electrum, New York (1986).

[31] W. Xue, Z. Xie, J. Yi, J. Chen, Scripta Mater. 67, 12 (2012) 963.

[32] A.V. Virkar, Key Eng. Mater. 153-154 (2009) 183.

[33] M. Turon-Vinas, M. Anglada, Dent. Mater. 34, 3 (2018) 365.

[34] M. Trunec, Ceram. Silik. 52, 3 (2008) 165.

[35] G.D. Quinn, R.C. Bradt, J. Am. Ceram. Soc. 90, 3
(2007) 673.

[36] G.D. Quinn, Ceram. Eng. Sci. Proc. 27, 3 (2006) 45.

[37] J. Lankford, J. Mater. Sci. Lett. 1, 11 (1982) 493.

[38] P.M. Kelly, L.R.F. Rose, Prog. Mater. Sci. 47, 5 (2002) 463.

[39] D.G. Lamas, N.E.W.D. Reca, Mater. Lett. 41 (1999) 204.

[40] F.F. Lange, J. Mater. Sci. 17 (1982) 225.

[41] P.F. Becher, Acta Metall. 34 (1986) 1885.

[42] R.M. McMeeking, A.G. Evans, J. Am. Ceram. Soc. 65 (1982) 242 .

[43] B. Budiansky, J.W. Hutchinson, J.C. Lambropoulos, Int. J. Solids Struct. 19 (1983) 337.

(Rec. 29/01/2020, Rev. 20/04/2020, Ac. 14/07/2020) 